\title{
KNOWLEDGE MANAGEMENT MODEL FOR FINANCIAL INTEGRATION OF ENTERPRISES
}

\section{VÍCTOR HUGO MEDINA GARCÍA, ABEL ANTONIO NAVARRETE LÓPEZ \& MIGUEL ÁNGEL OSPINA USAQUEN}

Universidad Distrital Francisco José de Caldas, Facultad de Ingeniería, Carrera 7 No 40B-53, Bogotá, Colombia

\section{ABSTRACT}

One of the problems of the interaction between the government, the university and the enterprises is financial integration with its consequent mechanisms of action that facilitate its strengthening, which is why the results of the research in this regard are presented. It is described a model for the integration of financial technology of digital business ventures involved in the business, educational, and government sectors with a high productive component to support digital marketing.

The model was developed based on knowledge management, taking into account: the knowledge resources or roles of the knowledge nodes that correspond to each of the sectors that interact with each other; the mechanisms or facilitators that provide actions to achieve this knowledge management; in addition to the indicators that allow the evaluation of their behavior; Finally, the relationships between the nodes of knowledge that describe the different types of intellectual capital that affect the phases in which knowledge is transformed were identified.

To integrate financial technology with government, business and university nodes, different indicators, dimensions, variables and interrelationships of the management and knowledge transfer models for digital businesses related to finance and digital marketing were considered. Using the Delphi method, a strategy to verify the model was proposed through the qualification of the relationships and the values taken by the variables, according to the perspective of a group of experts in the area, who provided their knowledge and experience, through of collecting their opinions.

KEYWORDS: Knowledge management; knowledge transfer; models; financial technology; digital marketing institutions

Received: Dec 08, 2020; Accepted: Dec 28, 2020; Published: Jan 04, 2020; Paper Id.: IJMPERDDEC202072

\section{INTRODUCTION}

It is of great relevance to understand how the business and academic sectors overlap with respect to knowledge management models, entrepreneurship, and their close relationship with innovation, business models, knowledge transfer and social appropriation of the same. However, when trying to define each of these disciplines it is evident that they are linked in some of their points of view. For example, from entrepreneurship, several definitions can be traced that contribute important concepts to the business models, transfer and social appropriation of knowledge that are studied from each of the knowledge nodes of the triple helix structure (state - university - enterprises) and intellectual capital (Etzkowitz \& Leydesdorff, 2000). Despite this, there is no single entrepreneurship model because the business opportunities and options are innumerable (Ries, 2012).

A model of technological innovation is evidenced by the analysis of "financial technology" which includes innovative financial solutions, enabled by information technologies (Thomas Puschmann, 2017). This provides the possibility to automate business processes carried out in the financial services industry and even 
allows the creation of new business models and new companies (Zavolokina et al., 2016). The financial technology model can be described as a facilitator of "financial innovation", a term that refers to the creation and popularization of new financial instruments, technology, institutions and markets (Tufano, 2003). The evaluation of this type of models allows to broaden the field of vision of the research in terms of the variety of existing ways of managing innovation processes, and in turn, allow to determine common elements that can be used to generate an integration of models.

A business model describes the logic of how an organization creates, delivers, and captures value (Spain, 2017), and must be structured in the value proposition or grouping of benefits that a enterprise offers and delivers to its customers (Osterwalder \& Pigneur, 2011). However, there is still no evidence of an adequate relationship between companies and higher education entities, since this knowledge implemented in companies is not directed in the industry-university order.

Therefore, this research analyzed various models, coming from both industry and academia, in search of the interaction between the actors and roles of the knowledge nodes that strengthen a triple helix structure. It should be noted that governments fund research at universities in the hope of improving business outcomes, yet there is little empirical evidence for this cause and effect relationship. An analysis is carried out on the existing models of management and knowledge transfer in digital businesses that allow to contribute to the visualization of a possible articulation of some of the models, orienting them to generate a better relationship between the various actors, as some multilateral platforms have achieved. (Osterwalder \& Pigneur, 2013).

\section{FOUNDATION OF KNOWLEDGE MANAGEMENT AND FINANCIAL TECHNOLOGY}

Next, the studied models that represent a contribution to the research and to the proposal of the model in theoretical and analytical terms are listed.

\subsection{Knowledge Management Models}

Despite the innumerable models that have been developed and implemented in organizations of different types, the most significant and relevant models that have contributed to the improvement of this topic in recent years are synthesized and that are a reference for any organization or person (academic or not) interested in this discipline.

In organizational management models knowledge, is that there are basically three ways to address it, given the object to manage: knowledge or intellectual capital, these two groups will typically have called pioneers models; or both if they are closely related to what are called hybrids (Medina, 2019):

- On the one hand, there are the classic knowledge management models, which are in charge of discriminating and locating those concepts inherent to the organization, which are essential for its correct management and administration. They are intended to identify the knowledge generation processes, as well as their design and the technology to structure and distribute it. It is a dynamic approach, more focused on processes than on asset identification. The most representative are: the knowledge creation model of Nonaka and Takeuchi; the KPMG Consulting model of Tejedor and Aguirre; the Arthur Andersen knowledge management model and the knowledge management assessment tool - KMAT.

- On the other hand, there are the models that are based on the measurement of intellectual capital, which seek to know in detail the intangible value of an organization through the quantification of the intellectual capital itself so that, once it is known, act accordingly with the profitability objectives of the enterprise or organization. These are 
static models, since they only describe and value the intangible assets of the organization at a given time. The most representative are: the Kaplan and Norton Balanced Scorecard; Edvinsson and Malone's Scandia Navigator; Sveivy's intangible asset monitor; the Intellect of Good model; the IICBS Innovation Intellectual Capabilities Benchmarking System model and the Social Capital Benchmarking System - SCBS model.

- Finally, there are hybrid models, which, as their name indicates, is an integration or combination of knowledge management models and models for measuring intellectual capital, and which constitute the modern trend in which organizations must evolve. They have generally been adaptations to pioneering models or applied or modern developments. The most representative are: The E.O. SECI by Eduardo Bueno; the Meritum model; the EKMF model of the European Union and the GC-U model of Medina, among others.

\subsection{Knowledge Transfer Models}

Also, it was necessary to review the knowledge transfer and research models as an articulating axis for the establishment of a new model. Knowledge management and intellectual capital are two measurable intangibles that can be recorded in nonfinancial statements, however, they are a source of valuable information to explain financial statements and facilitate decision-making (Castaño, 2014). Within the analyzed models, the following two groups are synthesized:

- Models towards the entrepreneurial University: Since the triple helix model highlighted the importance of the association between industry, academia and government in order to build a knowledge society in a balanced way (Etzkowitz \& Leydesdorff, 2000). Universities have gone from being producers of scientific documents to becoming providers of knowledge transfer.

In the academy, technological advances included in information technology (IT) that support knowledge management systems (KM) have been used, with the main objective of facilitating knowledge exchange (Fernández-López et al., 2018). Likewise, IT solutions in universities can influence business results through an evaluation of knowledge exchange processes and the conformation of its structure included in decision-making and knowledge management processes (Calvo et al., 2019).

Within the models that analyze the entrepreneurial university from the measurement of intellectual capital and knowledge management activities, the following are mentioned (Rodríguez, 2017):

- Intellectual capital measurement model of a university institution.

- Model for measuring collaborative knowledge management activities in a university institution.

- Model for measuring intellectual capital in the relationship between university, research and business.

Digital business models: Among the models that cover the transfer of knowledge, there are some oriented towards digital business, they are listed below in the order in which they were studied and used for the proposal of the model:

- Interactive Model (Rothwell and Zegveld, 1985).

- Business Model: Green Innovation (StartUp) (TOHANEAN student \& WEISS student, n.d.).

\subsection{Financial Technology Rationale}

Recent developments in information technology have led to continuous digitization processes not only towards increasing 
automation, but also to a fundamental reorganization of the financial services value chain with new business models and new players entering the market (Lee \& Shin, 2018). The term "fintech" in its abbreviation "fintech" reflects the scenario of this development of an information technology-induced transformation.

Financial technology is recognized as one of the most important innovations in the financial industry; covers solutions enabled by information technologies in ways that are innovative. Financial technology is evolving at a great speed, driven in part by the sharing economy, favorable regulation and information technologies (Thomas Puschmann, 2017), (Lee \& Shin, 2018).

Financial Technology Ecosystems are critical to fostering the kind of technological innovation necessary to make financial markets and systems more efficient and thus improve the overall customer experience. These fintech ecosystems can stimulate the broader local economy by attracting talented and ambitious people and becoming a place for creative thinking and entrepreneurial activity, taking on representative value within the context of technological innovation and entrepreneurship (Diemers et al., 2015).

\section{Participants of the Financial Technology Ecosystem}

The authors who propose the financial technology ecosystem (Diemers et al., 2015) indicate that entrepreneurs, the government and financial institutions are the main participants, such as:

- Governments must implement and enforce policies and a regulatory environment that facilitate ecosystem development.

- Financial institutions, including global and local banks, private equity shops, and venture capital funds can bring deep content and market expertise to the ecosystem.

- Entrepreneurs bring innovative and often disruptive technological solutions to the ecosystem.

\section{APPLIED METHODOLOGY FOR DEVELOPMENT MODEL}

The methodology applied to the development of this model was iterative, which allowed refining the results obtained in the investigation of the state of the art of the topics studied in the document. It consists of seven activities that describe the development cycle of the model to be treated, based on a systemic approach (Figure 1).

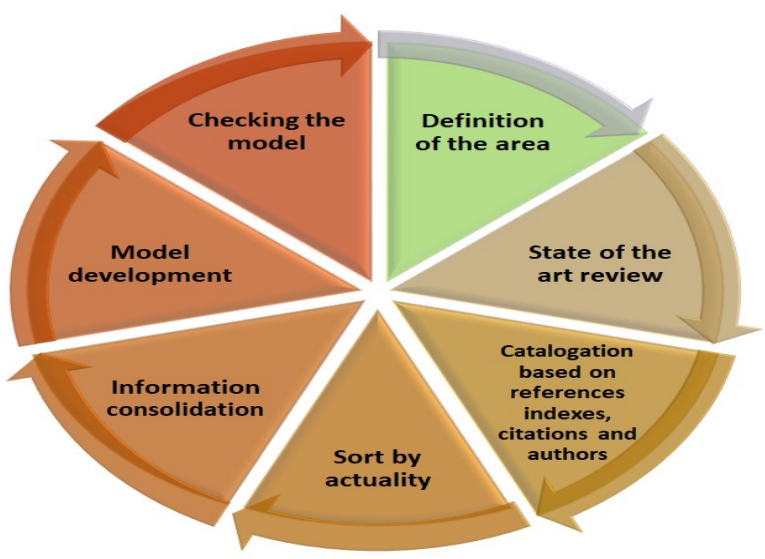

Figure 1: Methodological description. Source: Own elaboration

The activities developed in the methodology were: 
- Definition of the area: from a systemic approach, the specific area of interest was defined starting from those that focus on the problem to be treated. It was sought to reduce the complexity by directing the process to a specific area.

- State of the art review: the result of this activity identified the elements related to the approach to be investigated, found in databases such as: IEEE Xplore, Scopus, ScienceDirect, among others. The information selection criterion includes the news of the articles and books.

- Cataloging based on indexes of referencing, citation and authors: the articles that presented the highest index of referencing, citation and authors were selected. By referencing it is understood the number of citations towards the target article. Similarly, citation refers to the number of citations to other articles; and authors, such as the author's index that involves the number of citations of the author and his articles written.

- Sorting by topicality: the result of the previous phase was organized based on the criterion from least to oldest of the bibliography in order to find current scientific artifacts that show gaps in knowledge to be corrected.

- Consolidation of information: articles relevant to the topic were determined and selected for the study.

- Development of the model: the approach of the model was carried out in such a way that it transversally included the processes carried out by the identified actors, based on the consolidated information.

- Verification of the model: The model was contrasted using the modified Delphi method that structures the transversal communication process in a group of expert panelists on the subject, in order to analyze variables, relationships, predictions reached by related research with the members of the group, to later consolidate the results.

This method presents different variations according to need, reflecting changes from the traditional method. Some of the variations found in the literature and their comparison in terms of the type of method used, the number of rounds carried out, the number of panelists consulted, the existence of anonymity in the responses and a reduced period in the resolution of the surveys.

\section{KNOWLEDGE MANAGEMENT MODEL FOR INTEGRATION FINANCIAL OF INSTITUTIONS}

According to the models studied for the integration of financial technology and digital marketing focused on entrepreneurship, some of which explicitly use elements of knowledge management, a model is established that allows integrating some components of these and that relate the actors and processes in the business, university and government environment. It is validated using the Delphi method, with the evaluation of experts in the topics addressed.

The model transversally covers the processes carried out by the government, the enterprise and the university, focused on creating, managing and transferring knowledge, taking as a premise of development and integration the concept of financial technology and digital marketing, which can be expressed in the Figure 2. 


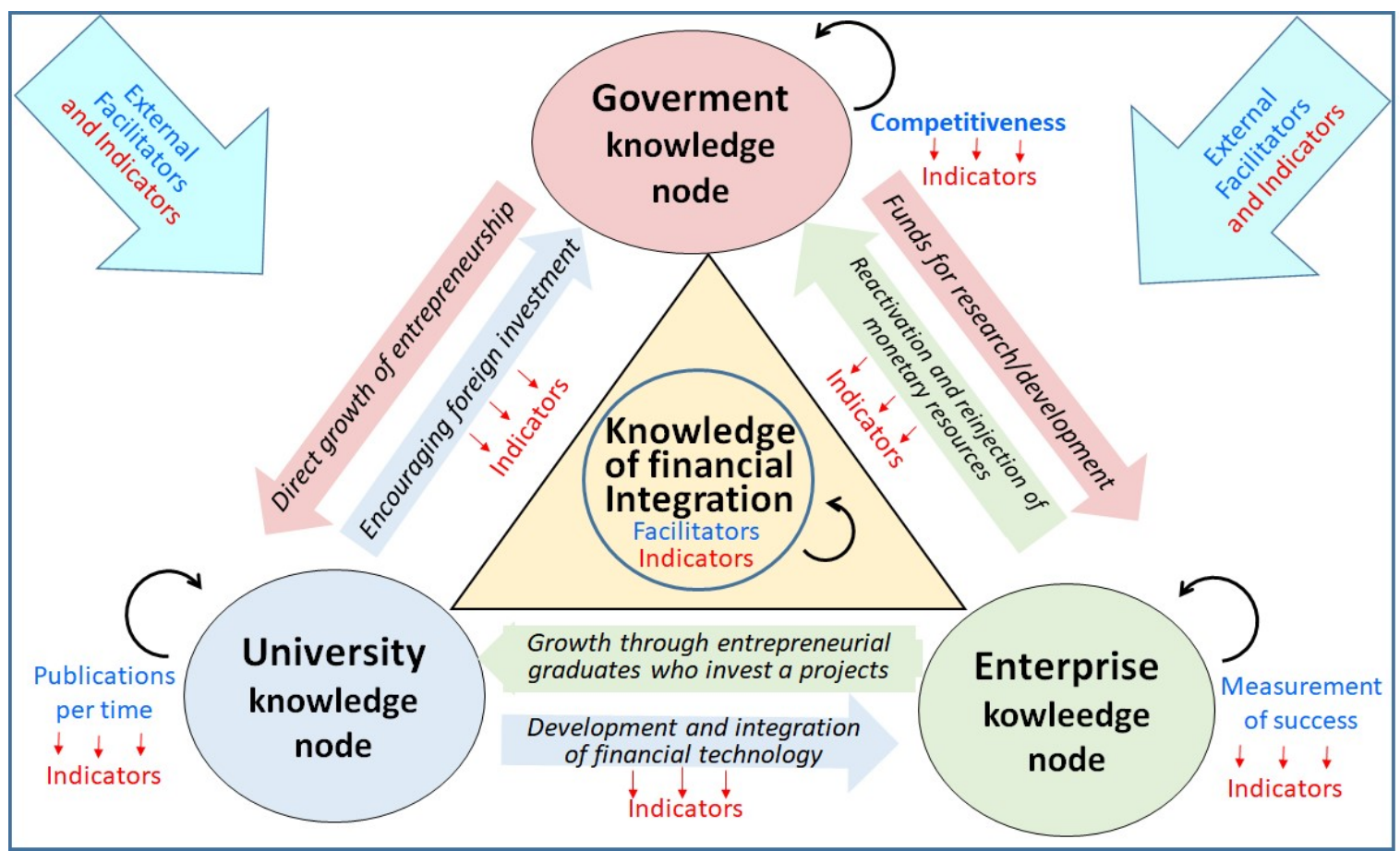

Figure 2: Knowledge management for financial integration of enterprises. Source: Own elaboration

\subsection{Knowledge Nodes and Facilitators of the Model}

As represented in Figure 2, the model is based on knowledge nodes (Government, Enterprise and University) that follow the triple helix structure. Nodes are knowledge-based resources, where knowledge is generated or transferred, perform various processing or treatment functions required internally or through links in a collaborative network (Medina, 2004). In each of its elements, the level of interaction and its role can be measured, framed in a model oriented to financial technology and digital marketing.

But, the main axis is the integration into a financial technology node, which is essential and fundamental in the proposed knowledge management model. It reflects the creative and operational dimension of the way of generating and disseminating knowledge among the members of the organization and also with other related agents. It constitutes the core or engine of the model and can be associated in analogy with a knowledge repository, which facilitates its effectiveness in different areas of knowledge, in different environments and with different user profiles. A knowledge repository is a set of data / information representing related experiences and their relationships, or related problems and their solutions. They include programs to search and retrieve information.

The facilitators in the model are the mechanisms or processes or elements that allow promoting the actions of the organization's policy, managing the indicators that facilitate the identification, development and retention of knowledge (Medina, 2004).

In the government node, the facilitators or processes that affect its behavior are: competitiveness with other cities evidenced in the amount of services available, the number of projects in progress and the level of access to information, the economic growth that is Inherent in the interactions with the other elements, the social support and investment, the amount of scholarships, incentives or aid that the government provides for research both to companies and universities, the infrastructure where the number of technological services are has access, and in physical matter, the number of companies 
around the roads and transit stops.

In the enterprise node, among the facilitators or processes that interact is the measurement of success from the value of creating a knowledge network, the database and customer capture, the years in the market and its scope of operation and the amount of appropriation of technological tools for administration and digital market, sales channels and provision of services, capital investment, its location, the capacity to use and disseminate knowledge, its annual productivity and if it is an exercise of Spin-off or Start-up.

In the university node, the facilitators or processes of the number of publications per time are presented, taking into account citation rates of articles and authors, the degree of transmission of information to the other members of the structure, the number of teachers dedicated to research and academic production carried out and related to projects developed with companies.

\subsection{Relationship between the Knowledge Nodes of the Model}

The government-enterprise relationship provides funds for research and development of programs and policies that support the industry, new programs, and financial growth through logistical support and a conceptual framework provided by the government. The enterprise-government relationship allows the reactivation and reinjection of monetary resources that come from the private sector to the public, international recognition due to good performance and therefore an increase in foreign investment.

The enterprise-university relationship is one of the main axes of the model by providing growth through entrepreneurial graduates who invest and finance financial technology startup projects, in addition to providing proximity to the business sector for the university and reducing the risks of launching new products through transition with research and extension institutes, providing industrial expertise to researchers along with business advice. The university-enterprise relationship favors the development and integration of financial technology and digital marketing in the enterprise, giving complementary knowledge and increasing its value and probability of being acquired. In this relationship, it is important to highlight the level of aptitude of the participants, that is, the support in postgraduate studies, the percentage of support ties between the university and the enterprise, their relational capital and the number of years of experience in the subject to work on, the investigative capacity of the enterprise, understood as literary production, number of employees and teachers in the research unit.

In contrast, the government-university relationship allows a direct growth of entrepreneurship in the university through funds, incentives, subsidies, policies to appropriate knowledge and support in the creation of research centers, infrastructure improvements and the creation of new universities. The university-government relationship consists of encouraging foreign investment, providing international recognition to the country for the production and quality of knowledge, and the increase and availability of knowledge for the government and society.

\subsection{Indicators of the Knowledge Management of the Model}

The variables, dimensions and indicators that stand out in the interaction of the three nodes and that allow establishing the real measurement of entrepreneurship with financial technology and digital marketing, are:

- Indicators of the enterprise knowledge node:

- Aplicación y proyección de empresas de tecnología financiera y mercadeo digital, que comprende (Zavolokina et 
al., 2016):

- People: Number of people involved in the conceptualization of financial technology and digital marketing in the last two years / Number of people involved in the conceptualization of financial technology and digital marketing in history.

- Location: Sectorization of regions and countries with an interest in promoting financial technology and digital marketing / All countries and regions.

- Organization: Number of companies based on the concept of financial technology and digital marketing in the last two years / Total companies.

- Financial education, defined by (Hatammimi \& Krisnawati, 2018):

- Money management: The ability of the business to use cash flow management and equity analysis to achieve financial objectives.

- Credit: The Enterprise knows how to obtain a loan and what the implications of this are.

- Debt management: The enterprise understands the use of debt as a tool to build assets, knowing how to measure and solve the debt problem.

- Risk management: The enterprise is able to protect assets and quality of life through the use of risk management strategies.

- Investment and retirement planning: Achieve financial goals through the application of investment and retirement strategies.

- Capacity and functionality of the enterprise, which is measured based on questions such as (Hatammimi \& Krisnawati, 2018):

- Does the enterprise have markets for business people to intervene in?

- Do you offer a payment, settlement and clearing tool?

- Indicators of the University knowledge node:

- Gross enrollment in tertiary education, which is defined by the percentage of the population in the age group corresponding to this level of education (Laidroo \& Avarmaa, 2019).

- Number of schools offering financial integration and digital marketing courses (Mei et al., 2018).

- Indicators of the Government knowledge node:

- Regulatory intervention, which defines the growth rate of financial technologies through 4 dimensions, (1) the option to defer, which allows to wait / learn more to see if a project will be profitable; (2) expansion option, which allows you to invest more in a project that is profitable; (3) option to abandon a project that is operating at a loss and sell or redeploy the assets; and (4) the option to contract, which allows reducing a project that is operating at a loss (Lee \& Shin, 2018).

- External variables, such as government regulations and technology development that are quite uncertain 
and their changes will have a significant impact on the growth and profitability of financial technologies (Lee \& Shin, 2018).

- Venture capital (VC) financing, which plays a major role in the early stages of innovation development (Wonglimpiyarat, 2019).

\section{TESTING MODEL USING THE DELPHI METHOD}

The Delphi method of verification was based on the principle of collective intelligence, through the application of questionnaires to a group of experts in three rounds and anonymously (Bruner, 2005; Hsu \& Sandford, 2007). Between each round, the results were statistically analyzed to structure new questionnaires that were redistributed to the experts Okoli \& Pawlowski (2004) The group of experts, in a third round, obtained the stability and consensus of the results by a mathematical procedure of aggregation of individual trials (Luna, Infante \& Martínez, 2006; Pozo, Gutiérrez, Pérez \& Rodríguez, 2007).

The reliability of the instrument was estimated by calculating the Cronbach's Alpha index or the consistency and precision with which the set of questions measured the behavioral aspect, reflecting the interrelation between its elements. Cronbach's alpha has typically been used to assess the reliability or internal consistency of a group of items that make up a scale. Cronbach's alpha has also been used in Delphi studies to measure the level of agreement among experts because Cronbach's alpha is based on the covariances between all the expert ratings and therefore its application in this research.

The research, in its exploratory phase, began with a qualitative approach by collecting data without numerical measurement, but with a dichotomous scale (yes / n0), to identify the attributes, characteristics and evaluation scales to build and evaluate the model in quantitatively for the next two rounds and to be able to estimate the reliability and validity indices (Brunner, 2005; (Luna, Infante \& Martínez, 2006); (Cruz, 2006).

In order to validate the conceptual model, a verification was carried out using the Delphi method, concentrating its application on obtaining the qualification of 47 experts of which, 16 are related to the new concept of financial technology and digital marketing (11 financial and 5 government), 20 related to the university ( 8 people from knowledge transfer offices, 7 professors, 3 graduates with spin-offs or start-ups and 2 students from research groups related to the project) and 11 people from companies interested in innovation and intellectual capital (6 managers and 5 people related to knowledge management logistics). The resolution of a survey is initially established in three rounds, each with a resolution time of 15 days, as shown in Table 2.

Table 2: Proposed modified Delphi method. Own elaboration

\begin{tabular}{|c|c|l|l|l|}
\hline Method & $\begin{array}{c}\text { \# of } \\
\text { Rounds }\end{array}$ & $\begin{array}{c}\text { \# of } \\
\text { Participants }\end{array}$ & $\begin{array}{c}\text { Anonymit } \\
\mathbf{y}\end{array}$ & $\begin{array}{c}\text { Surveys } \\
\text { resolution period }\end{array}$ \\
\hline Modified delphi & 3 & 47 & $\mathrm{Si}$ & 15 días \\
\hline
\end{tabular}

In the first stage, Cronbach's alpha was used to evaluate the internal consistency and dimensionality of the elements within each of the model domains, obtaining Cronbach's alpha indicators for each stage as follows: Stage 1, 0.839; Stage 2, 0.820; tests and final model, 0.863. The individual values of each item used in the instrument managed to exceed the threshold of 0.6. These values reflect a good consistency between the elements within the model and indicate that the elimination of any individual element would not increase the value of Cronbach's alpha. 
The following figure illustrates the testing methodology using the Delphi method.

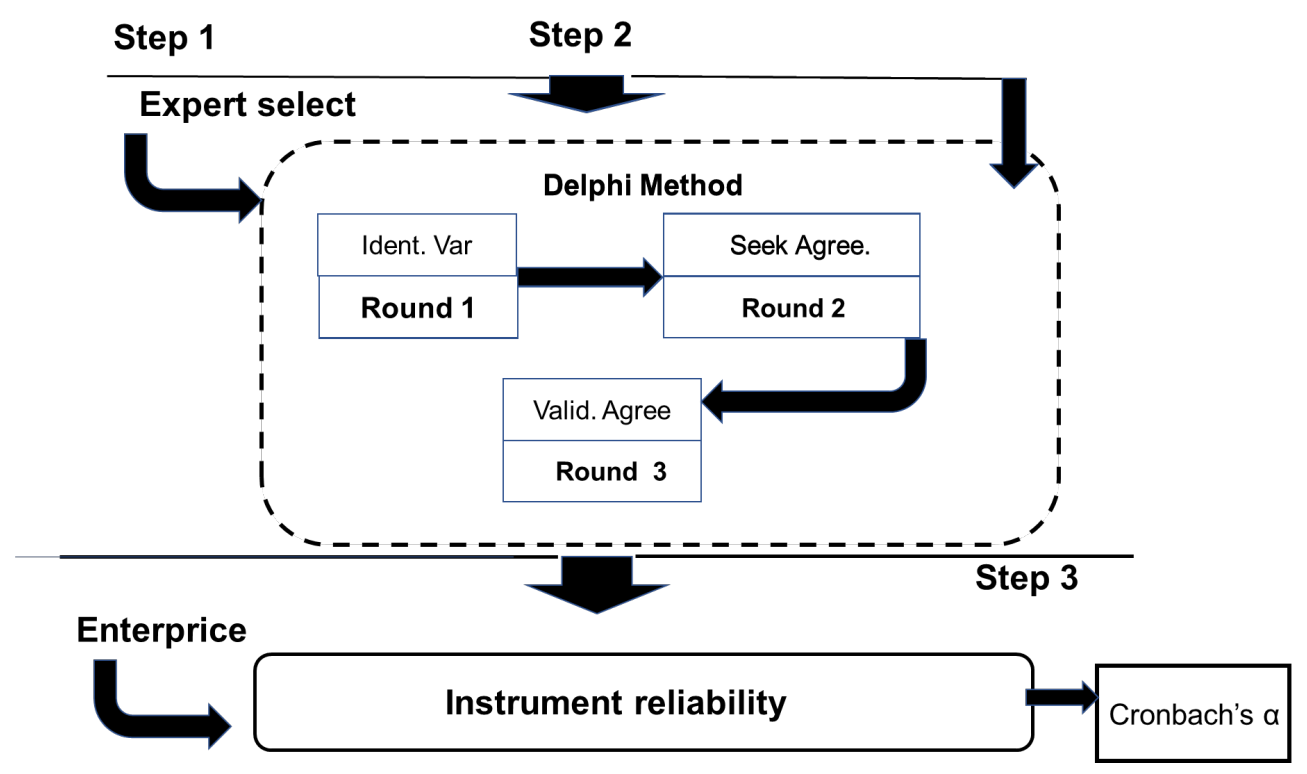

Figure 3: Application structure of the Delphi Method. Source: Adapted from Ocampo (2017).

Experts coincide in pointing out that changes in business models and digital marketing have reached entire industries such as transportation (UBER), accommodation (AIRBNB), television (NETFLIX), telephony (MEET GOOGLE), bookstore and large surfaces (AMAZON) (CCIT, 2017). The relationship of the client with the products and services changes and therefore the business models and digital marketing. New business and marketing models have emerged related to international remittances between individuals (TRANSFERWISE, 2011), robot-advisor and investment manager (BETTERMENT), financial intermediary (LENDING CLUB), which endanger the traditional financial sector. To avoid this, conglomerates of small and medium-sized technology companies are implemented that accelerate the process through two-way interaction with scientific research projects and the issuance of regulations.

Similarly, the experts conclude on the need to have a knowledge management model for entrepreneurship in financial technology integration that articulates the research university and the innovative industry, through the design of business promotion and competitiveness instruments. They agree on the need to design instruments or securities negotiable in the stock market as a result of investments in science, technology and innovation.

\section{CONCLUSIONS}

The management and transfer of knowledge from entrepreneurship to innovation oriented to the integration of financial technology and digital marketing, is in a phase of scientific research, since models have not been generated that correctly integrate the elements necessary to understand, adjust and define the processes and action plans for both the research units and the universities. However, there are models that allow intellectual capital to be managed from different perspectives in such a way that they represent greater income for the enterprise and / or are able to relate to academic institutions that, together with government plans, can make a correct use of knowledge.

The knowledge gap found in the management models for the integration of financial technology and digital marketing through technology is real, but as a result of the different existing models, guides can be found to establish parameters and metrics in organizations that promote management. and adequate knowledge transfer, through the study 
and promotion of products through emerging technological advances. Based on this as an alternative and integrative solution, a model based on industry, government and university nodes was proposed that allows the development of knowledge management and transfer aimed at interacting through relational computational systems between companies and government, supported by the tacit and fresh knowledge found in academic institutions and verified by a panel of experts that endorses its correct functioning, thus allowing, through an interaction of the three knowledge management nodes, the integration of financial technology and digital marketing.

\section{REFERENCES}

2. Bruner, J. (2005). A Delphi method of teaching applied phylospphy. Teaching philosophy 8 (3), 207-220.

3. Bueno, E. (1998). Boletín de Estudios Económicos. El capital intangible como clave estratégica en la competencia actual. Vol 53, No 164. Págs 207-229. Dialnet.

4. Calvo, N., Rodeiro-Pazos, D., Rodriguez-Gulias, M. J., \& Fernández-López, S. (2019). What knowledge management approach do entrepreneurial universities need? Information Systems, 85, 21-29. https://doi.org/10.1016/j.is.2019.06.002

5. Castaño, C. (2014). Una aproximación a la contabilidad del capital intelectual en el proceso de toma de decisiones: un estudio en el oriente antioqueño colombiano. Revista Visión Contable No 12. pag 130-160. Medellin. Colombia.

6. Canibano, L., Manuel, G.-A., Paloma, M., Olea, M., \& Sanchez, P. (n.d.). Measuring Intangibles to Understand snd Improve Innovation Management. Preliminary Results.

7. CCIT Cámara Colombiana de Informática y Telecomunicaciones (2017). Fintegración. Oportunidades para un sistema financiero. Colombia.

8. Diemers, D., Lamaa, A., Salamat, J., \& Steffens, T. (2015). Developing a FinTech ecosystem in the GCC. Strategy\&. PwC network.

9. España, J. de E. (2017). Guía Didáctica Modelo Canvas. Expertemprende Nevo Iniciativa. Junata de Extremadura. España.

10. Etzkowitz, H., \& Leydesdorff, L. (2000). The dynamics of innovation: From National Systems and "mode 2" to a Triple Helix of university-industry-government relations. Research Policy, 29(2), 109-123. https://doi.org/10.1016/S0048-7333(99)000554

11. Fernández-López, S., Rodeiro-Pazos, D., Calvo, N., \& Rodriguez-Gulias, M. J. (2018). The effect of strategic knowledge management on the universities' performance: an empirical approach. Journal of Knowledge Management, Vol. 22 No 3, 567-586. https://doi.org/10.1108/JKM-08-2017-0376

12. Hatammimi, J., \& Krisnawati, A. (2018). Financial literacy for entrepreneur in the industry 4.0 era: A conceptual framework in Indonesia. ACM International Conference Proceeding Series, 183-187. https://doi.org/10.1145/3285957.3285985

13. Laidroo, L., \& Avarmaa, M. (2019). The role of location in FinTech formation. Entrepreneurship and Regional Development. https://doi.org/10.1080/08985626.2019.1675777

14. Lee, I., \& Shin, Y. J. (2018). Fintech: Ecosystem, business models, investment decisions, and challenges. Business Horizons, 61(1), 35-46. https://doi.org/10.1016/j.bushor.2017.09.003

15. Luna, P., Infante, A. \& Martinez, F. J. (2006). Los Delphi como fundamento metodológico predictivo para la investigación en sistemas de información y tecnologías de la infor-mación (IS/ IT). Píxel-Bit. Revista de Medios y Educación, 26, 89-112. 
16. Marti, J. M. V., do Rosário Cabrita, M., Marti, J. M. V., \& do Rosário Cabrita, M. (2012). Social Capital Benchmarking System (SCBS). In Entrepreneurial Excellence in the Knowledge Economy (pp. 258-281). Palgrave Macmillan UK. https://doi.org/10.1057/9781137024077_8

17. Medina, V. H. (2004). Modelo Organizacional y Tecnológico de Gestión del Conocimiento en la Universidad: Aplicación en la Universidad Distrital Francisco José de Caldas. (Doctoral Thesis in Software Engineering), Universidad Pontificia de Salamanca, Madrid - España.

18. Medina, V. H. Medina, L. M. Tarazona, G. M. (2019). Investigación en Ingeniería apoyada por la gestión del conocimiento y la internet social. (Universidad Distrital F. J. C., Ed.) (1st ed.). Amadgraf Impresores Ltda. Bogotá.

19. Mei, S., Peiguang, L., \& Xiushan, N. (2018). Research on fintech industry development and talent training status. 13th International Conference on Computer Science and Education, ICCSE 2018, 384-387. https://doi.org/10.1109/ICCSE.2018.8468796

20. Ocampo, Jared R., Hernández-Matías, Juan Carlos, \& Vizán, Antonio. (2017). Method for estimating manufacturing competitiveness: The case of the apparel maquiladora industry in Central America. DYNA, 84(200), 97-106. https://dx.doi.org/10.15446/dyna.v84n200.60620

21. Okoli, C., \& Pawlowski, S. D. (2004). The Delphi method as a research tool: an example, design considerations and applications. Information \& management, 42(1), 15-29.

22. Osterwalder, A., \& Pigneur, Y. (2013). Generación de modelos de negocio. Editorial Deusto, 285. https://doi.org/10.1016/S0737-6782(96)90159-9

23. Ries, E. (2012). El método Lean Startup: Cómo crear empresas de éxito utilizando la innovación continua. 336. https://doi.org/10.1017/ CBO9781107415324.004

24. Rodríguez, L. Medina V. H. (2017). Un Modelo para la Investigación en Ingeniería Apoyado por la Gestión del Conocimiento Doctorando: 162.

25. Thomas Puschmann, F. (2017). Fintech. Business \& Information Systems Engineering, 59(1), 69-76. https://doi.org/10.1007/s12599-017-0464-6

26. Tohanean student, D., \& Weiss student, P. (n.d.). Digital Entrepreneurship And Green Business Model Innovation: Lean Startup Approaches.

27. TRANSFERWISE, (2011). La forma más barata y rápida de enviar dinero al extranjero. Accedido el 15 de mayo de 2020. https://transferwise.com/?clickref $=110019 q 6 S T w H \&$ partnerID $=1100167109 \&$ utm_medium $=$ affiliate\&utm_campaign $=0 \& a d r e f=\& u t m \_s o u r c e=$ destinoreinounido\&partnerizecampaignID=11011644

28. Tufano, P. (2003). Financial innovation. Chapter 06 in Handbook of the Economics of Finance, vol. 1, Part 1, pp 307-335 from Elsevier.

29. Wonglimpiyarat, J. (2019). Crowd funding dynamics for venture and innovation development. International Journal of Technology, Policy and Management, 19(1), 1-13. https://doi.org/10.1504/IJTPM.2019.097989

30. Zavolokina, L., Dolata, M., \& Schwabe, G. (2016). FinTech-What's in a Name? https://doi.org/10.5167/uzh-126806 